\title{
Las cláusulas sociales en el proyecto de Ley de Contratos del Sector Público y el nuevo paradigma de la contratación pública
}

\author{
Aritz Romeo Ruiz
}

DOI: https://doi.org/10.47623/ivap-rvap.108.2017.04

\begin{abstract}
Sumario: I. Las cláusulas sociales como instrumento para el desarroIlo de la estrategia EUROPA 2020.-II. La jurisprudencia del TJUE, de BEENTJES a REGIOPOST, un camino entre la contratación social y la libre competencia. II.1. La STJCE, de 20 de septiembre de 1988, Grebroederes Beentjes (As. C 31/87). II.2. La STJCE, de 26 de septiembre de 2000, Comisión c. República Francesa (As. C 225/98). II.3. La STJCE, de 17 de septiembre de 2002, Concordia Bus Finland Oy Ab (As. C 513/99). II.4. La STJCE, de 4 de diciembre de 2003, EVN AG., (As. C 448/01). II.5. La STJCE, de 3 de septiembre de 2008, Rüffert, (As. C 346/06). II.6. La STJCE, de 17 de noviembre de 2015, RegioPost, (As. C 115/14). - III. la codificación de la doctrina del TJCE en las Directivas Europeas. III.1. La Directiva 2004/18/CE, pionera en la articulación de criterios sociales. III.2. Las cláusulas sociales en las Directivas de 2014. - IV. Ia aplicación práctica de criterios sociales a través de la doctrina de los tribunales administrativos de contratos públicos. $-\mathrm{V}$. los criterios sociales en el Proyecto de Ley de Contratos del Sector Público.-VI. Conclusiones.-VII. Bibliografía.
\end{abstract}

\section{Las cláusulas sociales como instrumento para el desarrollo de la estrategia EUROPA 2020}

La contratación pública ha adquirido una enorme relevancia en la economía, situándose en torno al 18'5\% del PIB nacional español(1), en línea con los denominados países desarrollados, en los cuales alcanza el 15\%, y con la propia Unión Europea, donde la contratación pública alcanzó los 1.770 miles de millones de euros en 2012 (2).

(1) CNMC, Análisis de la contratación pública en España: oportunidades de mejora desde el punto de vista de la competencia. Madrid, 2015, pág. 3. Ese mismo dato es referido por el Observatorio para la Contratación Pública, http://www.obcp.es/, según datos de 2013.

(2) COMISIÓN EUROPEA, Public Procurement Indicators 2012. Bruselas, 2014, pág. 6. 
Dado su peso específico en el contexto económico europeo, la contratación pública ha de avanzar hacia una mayor transparencia y eficiencia, y debe procurar el beneficio, en primer lugar de los ciudadanos, pero también de los poderes públicos y de las empresas(3). Para ello, es vital que los procedimientos de contratación se desarrollen según los principios de transparencia, eficiencia e integridad, con el fin de salvaguardar la calidad en la prestación de servicios públicos y servir al interés público, tal y como ha recomendado la OCDE (4).

La garantía del interés público y el beneficio de los ciudadanos en la gestión de la contratación pública han de tener en cuenta la perspectiva social, como elemento necesario para lograr el triple objetivo de crecimiento sostenible, inteligente e integrador que la Comisión Europea ha marcado en su Comunicación Europa 2020(5).

Para lograr tales fines, la contratación pública es un instrumento adecuado a través del cual se debe contribuir a la puesta en marcha de políticas sociales, ambientales, de innovación, y de promoción de las PYMES, sin vulnerar los principios de la contratación pública (6), de manera que, además de servir a la ejecución de obras o a la prestación de servicios públicos, incida en las políticas sociales y ambientales(7). Todo ello se compele, además, de las recomendaciones del Libro Verde sobre la Contratación Pública en la Unión Europea (8), en el cual el CESE aboga a favor de que la contratación pública tenga en cuenta las prioridades europeas, especialmente en materia social (9).

(3) CNMC, Análisis de la contratación pública en España: oportunidades de mejora desde el punto de vista de la competencia. Cit., pág. 4.

(4) OCDE, Corruption in public procurement, 2016, pág. 4.

(5) COMISIÓN EUROPEA, Europa 2020. Una estrategia para un crecimiento inteligente, sostenible e integrador. Bruselas, 2010.

(6) MARTÍNEZ FERNÁNDEZ, José Manuel, Avanzando en la Contratación socialmente responsable: de la recomendación a la obligación. Observatorio de la Contratación Pública, 2011 (documento electrónico).

(7) MARCHAL ESCALONA, Nuria, "Las cláusulas sociales en los contratos públicos: ¿son contrarias al derecho comunitario?», en Bitácora Millenium DIPr, núm. 3, 2016, pág. 12-26, pág. 13.

(8) COMISIÓN EUROPEA, Libro Verde sobre Contratación Pública en la Unión Europea. Bruselas, 1996, pág. 33 y 43-44.

(9) CONSEJO ECONÓMICOY SOCIAL EUROPEO, Dictamen de 29 de mayo de 1997, sobre el Libro Verde sobre Contratación Pública en la Unión Europea. Bruselas, 1997. También la Comisión Europea ha ahondado en la conveniencia de incorporar criterios sociales, para avanzar hacia la contratación pública responsable, entendiendo por tal la compra pública verde, innovadora y social, a través de COMISIÓN EUROPEA, Comunicación interpretativa de la Comisión, sobre la legislación comunitaria de contratos públicos y las posibilidades de integrar aspectos sociales en dichos contratos. Bruselas, 2001. También en COMISIÓN EUROPEA, Adquisiciones sociales. Una guía para considerar aspectos sociales en las contrataciones públicas. Bruselas, 2010. En este sentido se han manifestado GALLEGO CÓRCOLES, Isabel: "Cláusulas sociales, contratación pública y jurisprudencia delTJUE», en Contratación Administrativa Práctica, núm. 113, 2011, págs. 64-69, pág. 64 y MEDINA ARNAIZ, Teresa: «Más allá del precio: las compras públicas con criterios de responsabilidad (I)", en Actualidad Administrativa, núm. 113, 2013. 
Con todo, se perfila la posibilidad de incorporar criterios sociales en los contratos del sector público, aunque fijando como límites que los mismos queden claramente reflejados en el anuncio de licitación, en pos del principio de transparencia, y que no resulten discriminatorios para los posibles licitadores de los Estados, en base a los principios de igualdad y no discriminación y libre concurrencia. Asimismo, se establece que los criterios sociales habrán de estar directamente relacionados con el objeto del contrato (10).

La voluntad de las instituciones europeas por utilizar la contratación pública como un instrumento a través del cual desarrollar políticas públicas de integración social y de desarrollo ambientalmente sostenible y responsable, encuentra su fundamento último en el artículo 9 delTFUE, que establece que «En la definición y ejecución de sus políticas y acciones, la Unión tendrá en cuenta las exigencias relacionadas con la promoción de un nivel de empleo elevado, con la garantía de una protección social adecuada, con la lucha contra la exclusión social y con un nivel elevado de educación, formación y protección de la salud humana». Todo lo cual se encuentra indefectiblemente unido a un principio básico de la Unión como lo es el principio de solidaridad(11).

En definitiva, la contratación pública debe ser concebida como un instrumento de los poderes públicos para el cumplimiento de sus fines o de desarrollo políticas públicas, debiendo permitir la consecución de objetivos sociales, ambientales o de investigación(12) y orientarse a la consecución de objetivos sociales y ambientales" (13).

Así, los principios que rigen la contratación pública (igualdad de oportunidades y accesibilidad universal, igualdad de trato y no discrimina-

(10) RAMOS PÉREZ-OLIVARES, Alfredo: "Las cláusulas sociales en la regulación de los contratos del sector público tras el R.D. Leg. 3/2011», en Contratación Administrativa Práctica, núm. 119, mayo de 2012, págs. 30-51.

(11) GIMENO FELIÚ, José María: «Un paso firme en la construcción de una contratación pública socialmente responsable mediante colaboración con entidades sin ánimo de lucro en prestaciones sociales y sanitarias», en Observatorio de la Contratación Pública, 2016 (documento electrónico).

(12) GIMENO FELIÚ, José María: «Las nuevas Directivas - cuarta generación - en materia de contratación pública. Hacia una estrategia eficiente de compra pública», en Revista española de Derecho Administrativo, núm. 159, 2013, pág. 3. En sentido similar AYMERICH CANO, Carlos, y FERREIRA FERNANDEZ, Antonio Javier: «El tratamiento de las cláusulas sociales en la normativa reguladora de la Contratación Pública. En particular las cláusulas sociales como criterio de adjudicación de los contratos", en PERNÁS GARCÍA, Juan José, RODRÍGUEZ-ARANA MUÑOZ, Xaime (coords.), JINESTA LOBO, Ernesto, (Dir.), El Derecho Administrativo en perspectiva: en homenaje al profesor José Luis Meilán Gil. RAP editores, Buenos Aires, 2014, tomo II, pág. 33-52, pág. 34.

(13) GIMENO FELIÚ, José María: La nueva contratación pública europea y su incidencia en la legislación española. Civitas, Madrid, 2006, pág. 47. En sentido similar se ha manifestado el mismo autor en El nuevo paquete legislativo comunitario sobre contratación pública. De la burocracia a la estrategia. Thomson Aranzadi - Ministerio de Economía y Competitividad - Universidad de Zaragoza, Cizur Menor (Navarra), 2014, pág. 39 y ss. 
ción, proporcionalidad, confianza legítima, publicidad y transparencia y confidencialidad), han de verse complementados por la búsqueda de fines sociales y ambientales que los poderes públicos podrán tener en cuenta a la hora de desarrollar los procedimientos de contratación pública. Dicha conjunción resulta, además de posible, «racional, eficaz, sinérgica e incluso rentable» (14).

\section{La jurisprudencia delTJUE, de BEENTJES a REGIOPOST, un camino entre la contratación social y la libre competencia}

La introducción de cláusulas sociales y ambientales en la contratación pública está condicionada al impacto del derecho europeo, tanto por la jurisprudencia del TJUE como por las directivas de contratación pública que, en buena medida, han codificado la jurisprudencia comunitaria y que son el marco jurídico fundamental del que emana el derecho de contratos públicos de los Estados miembros (15).

\section{II.1. La STJCE, de 20 de septiembre de 1988, Grebroederes Beentjes (As. C 31/87)}

La sentencia Beentjes(16), fue pionera en la jurisprudencia europea en cuanto a la admisión de la incorporación de criterios sociales.

EI TJCE admitió la inclusión de cláusulas con contenido social, pero siempre condicionándolo a que la misma no vulnere la igualdad de licitadores y la libre competencia entre empresas de los diferentes Estados miembros, y siempre que se respete el principio de publicidad(17). De

(14) LESMES ZABALEGUI, Santiago: “Contratación pública y discriminación positiva. Cláusulas sociales para promover la igualdad de oportunidades entre mujeres y hombres en el mercado laboral», en Lan Harremanak, núm. 13, 2005, pág. 53-86, pág. 66. Similar opinión han mostrado MELERO ALONSO, Eduardo y ESPÍN SÁEZ, Maravillas: «El contrato administrativo como instrumento para ejercer políticas públicas. Fomento del empleo estable y contratación con empresas de trabajo temporal», en Revista Jurídica de la Comunidad de Madrid, núm. 1, 1999, documento electrónico.

(15) Sobre las cláusulas sociales y ambientales en el marco europeo, vid. CARANTA, Roberto yTRYBUS, Martin (Eds.): The Law of Green and Social Procurement in Europe (European Procurement Law). DJOF Publishing, Copenhague, 2010.

(16) En Beentjes el Tribunal analizó la exclusión de un licitador en un contrato de obras por entender que carecía de capacidad para contratar personas que se encontraran en situación de desempleo de larga duración.

(17) GALLEGO CÓRCOLES, Isabel: "Cláusulas sociales, contratación pública y jurisprudencia del TJUE», cit., p. 66. En similar sentido MEDINA JURADO, Purificación: "Las cláusulas sociales en la contratación pública: retos y perspectivas», en Revista CEMCl, núm. 7, 2010, pág. 13 
este modo, tras la sentencia se aprecia una visión de prevención ante la incorporación de cláusulas de contenido social, que quedan supeditadas a respetar las normas de la competencia(18).

\section{II.2. La STJCE, de 26 de septiembre de 2000, Comisión c. República Francesa (As. C 225/98)}

La sentencia Comisión c. Francia(19) admitió la incorporación, como criterio de adjudicación de un contrato, de consideraciones relacionadas con la lucha contra el desempleo, reafirmando los condicionantes establecidos por la sentencia Beentjes. Como puede apreciarse, el Tribunal de Justicia prevé tales requisitos desde la perspectiva de procurar garantizar la libre competencia, a la cual se supedita la introducción de cláusulas con contenido social (20).

\section{II.3. La STJCE, de 17 de septiembre de 2002, Concordia Bus Finland Oy $A b$ (As. C 513/99)}

En la sentencia Concordia Bus(21), el Tribunal determinó que es compatible con el Derecho comunitario que a la hora de adjudicar a un licitador un contrato teniendo en cuenta la oferta más ventajosa, la entidad adjudicadora también considere criterios relacionados con la protección del medio ambiente, siempre y cuando los mismos estén relacionados con el objeto del contrato, no atribuyan a dicha entidad una libertad incondicional de elección, además de los ya establecidos por las sentencias Comisión c. Francia, y Beentjes.

(18) GONZÁLEZ GARCÍA, José Vicente: «Sostenibilidad social y ambiental en la Directiva 2014/24/ UE de Contratación Pública» en Civitas. Revista Española de Derecho Europeo, núm. 56, 2015, págs. 13-42, pág. 24.

(19) En la Sentencia Comisión c. Francia, el Tribunal de Justicia analizaba un recurso de la Comisión Europea frente a la inclusión expresa, como criterio de adjudicación en determinados anuncios de licitación, de medidas en relación con el empleo, encaminadas a la lucha contra el desempleo.

(20) GONZÁLEZ GARCÍA, José Vicente: «Sostenibilidad social y ambiental en la Directiva 2014/24/ UE de Contratación Pública», cit., pág. 24.

(21) El litigio versaba sobre la inclusión en anuncio de licitación criterios como el precio global para la explotación, la calidad de los autobuses y la gestión por parte del empresario en materia de calidad y medio ambiente, como elementos para valorar la oferta más favorable desde el punto de vista económico global. Al respecto, Tribunal de Justicia consideró que, en la valoración de una oferta, pueden tenerse en cuenta criterios no exclusivamente económicos, tal y como señala BALLINA DíAZ, Diana: "Las cláusulas sociales en la contratación pública», en El consultor de los Ayuntamientos y de los Juzgados, núm. 3, 2011, págs. 296-302, pág. 300. 


\section{II.4. La STJCE, de 4 de diciembre de 2003, EVN AG., (As. C 448/01) (22)}

La sentencia $E V N$, recopiló doctrina fijada en Beentjes y en Concordia Bus(23) y exige, para la validez de una cláusula de contenido social o ambiental, en este caso como criterio de adjudicación, los mismos requisitos contenidos en las anteriores sentencias.

\section{II.5. La STJCE, de 3 de septiembre de 2008, Rüffert, (As. C 346/06)}

La sentencia Rüffert(24) el Tribunal consideró que la protección que la Directiva 97/71 da a los trabajadores, es una protección de máximos, e interpretó que una medida de protección de las condiciones laborales de los trabajadores que operan en una obra pública podría vulnerar la prohibición de imponer restricciones a la libre prestación de servicios dentro de la Comunidad para los nacionales de los Estados miembros establecidos en un país de la Comunidad que no sea el destinatario de la prestación, tal y como recoge el artículo 49 del Tratado Constitutivo de la Comunidad Europea .

Sin embargo, sí considera la sentencia Rüffert que, en virtud del artículo 3.1 de la Directiva 96/71, "deben garantizarse a los trabajadores desplazados, en relación con las prestaciones de servicios transnacionales en el sector de la construcción, las condiciones de trabajo y de empleo relativas a las materias a que se refieren las letras a) a g) de dicha disposición, entre las que figuran, en la letra c), las cuantías de salario mínimo". No obstante, la sentencia limita dichas condiciones de empleo a aquellas que estén fijadas mediante «disposiciones legales, reglamenta-

(22) La sentencia EVN abordó un litigio en torno a un contrato que se licitó mediante procedimiento abierto para el suministro de electricidad. Se pretendía la celebración de un contrato marco, del que emanaban distintos contratos de aplicación, que tenían por objeto el suministro de electricidad a los servicios de la Administración federal en el Land austriaco de Carintia. El criterio de adjudicación fijado se refería a la oferta económicamente más ventajosa, que se establecería usando como criterio la incidencia de las prestaciones en el medio ambiente. El proveedor estaba obligado a comprometerse a suministrar electricidad generada a partir de fuentes de energía renovables, en la medida que técnicamente resultara posible, y a no suministrar, en ningún caso, electricidad generada a través de fisión nuclear.

(23) GONZÁLEZ GARCÍA, José Vicente: "Sostenibilidad social y ambiental en la Directiva 2014/24/ UE de Contratación Pública», cit., pág. 25.

(24) La sentencia Rüffert analiza si es compatible con el Derecho comunitario la norma del Land de Baja Sajonia, de establecer como condición de ejecución de un contrato de obra pública que la empresa adjudicataria abone a los trabajadores el salario mínimo establecido en el convenio colectivo aplicable en el lugar en que se ejecutan las obras. Al tratarse de una situación con intereses que afectan a más de un Estado miembro, el litigio se resuelve con aplicación de la Directiva 96/71/CE, de 16 de diciembre, sobre el desplazamiento de trabajadores efectuado en el marco de una prestación de servicios. 
rias o administrativas, y/o mediante convenios colectivos o laudos arbitrales declarados de aplicación general».

La doctrina Rüffert, en cierto modo alteró la tendencia favorable a incluir consideraciones de tipo social en los pliegos de contratación. Doctrina que ha sido superada por la Directiva 2004/18/CEt(25).

\section{II.6. La STJCE, de 17 de noviembre de 2015, RegioPost, (As. C 115/14)}

La sentencia RegioPost(26) se aparta de la doctrina Rüffert, determinando que es compatible con el Derecho comunitario la exclusión de un licitador y de sus subcontratistas que "se nieguen a comprometerse, mediante una declaración escrita que deberá presentarse junto con la oferta, a pagar al personal que llevará a cabo las prestaciones objeto del contrato público considerado un salario mínimo fijado por la normativa» (27).

De este modo, la normativa que obliga a los adjudicatarios de un contrato público y a las empresas subcontratadas por aquéllos a remunerar al personal que va a ejecutar la prestación objeto del contrato, un salario mínimo establecido, es compatible con el Derecho comunitario, y estaría plenamente justificada, por lo que no entraría en colisión con el principio de libre prestación de servicio. Puede afirmarse que la sentencia RegioPost supone un importante paso adelante, apartándose la arriesgada doctrina jurisprudencial que se estableció Rüffert. Aunque no podemos obviar el desequilibrio existente entre la libertad de prestación de servicios y la libertad de circulación, por un lado, y los derechos de los trabajadores por el otro (28). Lo anterior deja en evidencia que apremia la creación de un marco básico europeo de protección social.

(25) La Directiva 2004/18 CE establece, en su artículo 34, que «las leyes, reglamentaciones y convenios colectivos tanto nacionales como comunitarios, vigentes en materia de condiciones de trabajo, se aplicarán durante la ejecución de un contrato público, siempre que dichas normas, así como su aplicación, se ajusten al Derecho comunitario». Además, determinó que la protección de la Directiva 97/71 para situaciones transfronterizas es una protección "de mínimos», vid. GALLEGO CÓRCOLES, Isabel: "Cláusulas sociales, contratación pública y jurisprudencia de TJUE», cit., pág. 70.

(26) En la sentencia RegioPost el Tribunal de Justicia una licitación mediante procedimiento abierto, dividida en dos lotes, que inició el ayuntamiento de Landau (Renania-Palatinado), para contratar los servicios postales de municipio. Además, preveía la celebración de un contrato marco de servicios postales con una duración de dos años. Sobre la STJCE RegioPost, vid., MARCHAL ESCALONA, Nuria: "Las cláusulas sociales en los contratos públicos: ¿son contrarias al Derecho comunitario?», en Bitácora Millenium DIPr. Derecho Internacional Privado, núm. 3, 2016, pág. 12-26.

(27) Un análisis de la sentencia RegioPost puede encontrarse en MORCILLO MORENO, Juana: "Las cláusulas sociales en la contratación pública como garantía al dumping social intracomunitario", en Revista Aragonesa de Administración Pública, núm. 47-48, 2016, págs. 180-209.

(28) MARCHAL ESCALONA, Nuria: «Las cláusulas sociales en los contratos públicos: ¿son contrarias al Derecho comunitario?», cit., pág. 26. 
Un mínimo análisis del camino recorrido por la doctrina jurisprudencial europea, nos muestra de manera nítida la paulatina asunción de la introducción de criterios sociales y ambientales en la contratación pública, marcada por una clara dialéctica entre el principio de la libre competencia y la contratación socialmente responsable. Tensión en la cual, la balanza siempre bascula a favor de la libre competencia, que opera como principal condicionamiento y límite a la introducción de criterios sociales(29), aunque sin impedir la posibilidad de incorporar consideraciones de tipo social en los procedimientos de contratación.

\section{La codificación de la doctrina delTJCE en las Directivas Europeas}

\section{III.1. La Directiva 2004/18/CE, pionera en la articulación de criterios sociales}

La Directiva 2004/18/CE, pionera en la regulación de las cláusulas sociales en la contratación pública (30), positivizó la doctrina jurisprudencial e incorporó por vez primera la posibilidad de incorporación de criterios de carácter social, fundamentalmente en la fase de ejecución de los contratos públicos.

La Directiva supeditó la inclusión de criterios sociales y ambientales en la contratación pública al cumplimiento de los requisitos establecidos por la jurisprudencia del Tribunal de Justicia de la Unión Europea. A saber, que exista vinculación con el objeto del contrato, que no otorguen al poder adjudicador un poder ilimitado de elección, que consten expresamente mencionados en el anuncio de licitación o en el pliego de condiciones del contrato, y que respeten los principios fundamentales del Derecho Europeo, especialmente, los principios de libertad de establecimiento y prestación de servicios, igualdad y no discriminación, proporcionalidad, y transparencia (31).

Con todo, la Directiva 2004/18/CE, que contiene mayores avances en cuanto a criterios ambientales que cuando se trata de criterios socia-

(29) GONZÁLEZ GARCÍA, José Vicente: «Sostenibilidad social y ambiental en la Directiva 2014/24/ UE de Contratación Pública», cit., págs. 13-42.

(30) VILLALBA PÉREZ, Francisca: "La dimensión social de la contratación pública. El sector de la discapacidad en la Ley de Contratos del Sector Público", en Revista Andaluza de Administración Pública, núm. 74, 2009, pág. 74. En similar sentido MEDINA JURADO, Purificación: "Las cláusulas sociales en la contratación pública: retos y perspectivas", cit., pág. 14. También PÉREZ ALCÁNTARA, A.J.: "Los principios de la contratación pública y la Ley de Contratos del Sector Público», en El Consultor de los Ayuntamientos y de los Juzgados, núm. 21, 2008, pág. 3517.

(31) MEDINA JURADO, Purificación: "Las cláusulas sociales en la contratación: retos y perspectivas", cit., pág. 14. 
les (32), centra las posibilidades de incorporar cláusulas con contenido social en dos direcciones principales: las reservas a centros especiales de empleo, y su consideración como condiciones de ejecución de los contratos, al tiempo que hace hincapié en la necesidad de garantizar el cumplimiento por parte de los licitadores de las obligaciones en materia de fiscalidad, protección del medio ambiente, y las disposiciones de protección y condiciones de trabajo.

\section{III.2. Las cláusulas sociales en las Directivas de 2014 (33)}

La revisión de las directivas de 2004, efectuada a través de la directivas de cuarta generación, se caracteriza fundamentalmente por procurar la simplificación y la eficiencia (34), huyendo de normas "excesivamente rígidas e invasivas» (35).

En este sentido, la Directiva 2014/24/UE que se enmarca en la Estrategia Europa 2020, continúa la línea de concebir la contratación pública como un instrumento para contribuir al logro de una mayor sostenibilidad ambiental y social. Por consiguiente, contiene avances en materia de contratación socialmente responsable, al tiempo que pone a disposición de los Estados, dentro del marco de la ejecución de los contratos públi-

(32) Sobre la incorporación de criterios ambientales en la contratación pública en la etapa previa a la vigente Directiva 2014/24/UE, vid., PERNAS GARCÍA, Juan José: Contratación pública verde. La Ley Wolters Kluwer, Las Rozas (Madrid, 2011). También GIMENO FELIÚ, José María: La contratación pública europea y su incidencia en la legislación española. La necesaria adopción de una nueva ley de contratos públicos y propuestas de reforma. Thomson Aranzadi, Cizur Menor (Navarra), 2006. KUNZIL, P.: "Green procurement under the new regime», en NIELSE, R., TREUMER, S.: The new EU procurement directives. DJ F Publishing, Copenhague, 2005. LEFĖVRE, P. : "Les considérations sociales et environnementales dans les marchés publics européens», en Journal des Tribunaux. Droit européen, núm. 7, 2000.

(33) Sobre el nuevo paquete de Directivas en materia de contratación pública, vid., GIMENO FELIÚ, José María: El nuevo paquete legislativo comunitario sobre contratación pública. De la burocracia a la estrategia. (El contrato público como herramienta de liderazgo institucional de los poderes públicos). Aranzadi, Cizur Menor (Navarra), 2014. También MORENO MOLINA, José Antonio: "La cuarta generación de Directivas de la Unión Europea sobre contratos públicos», en GIMENO FELIÚ, José María, BERNAL BLAY, Miguel Ángel, (Coords.), et. al.: Observatorio de los Contratos Públicos, 2012. Thomson Reuters Aranzadi, Cizur Menor (Navarra), 2013. RAZQUIN LIZARRAGA, Martín María: "Las nuevas Directivas sobre contratación pública de 2014: aspectos clave y propuestas para su transformación en España», en Revista de Administración Pública, núm. 196, págs. 97-113.

(34) GIMENO FELIÚ, José María: «Novedades del Anteproyecto de Ley de Contratos del Sector Público. La transposición de las Directivas de contratación pública en España», ponencia presentada en el Congreso Internacional sobre Contratación Pública, celebrado en Cuenca los días 21 y 22 de enero de 2016, organizado por el Observatorio de Contratación Pública y la Universidad de Castilla La Mancha.

(35) BENACCHIO, G.A.: "Verso le Direttive di quarta generazione», en BENACCHIO, G.A., y COZZIO, M.: Gli appalti pubblici: tra regole europee e nazionali. Egea, Milano, 2012, págs. 3-28, pág. 8. 
cos, de instrumentos jurídicos Ilamados a garantizar el cumplimiento de los preceptos legales y convencionales que establecen compromisos en materia social y ambiental.

Destaca la incorporación, en el artículo 18.2 de la directiva, es decir, a continuación de proclamar los principios fundamentales de la contratación pública, de un mandato a los Estados miembros para que tomen las medidas pertinentes a fin de garantizar el cumplimiento de las obligaciones sociales, ambientales y laborales por parte de los operadores económicos.

Además, la directiva prevé la inclusión de criterios sociales en diferentes estadios de la contratación como lo son la definición del objeto del contrato, las causas de exclusión de contratistas, en la regulación de los criterios de adjudicación, así como en las condiciones de ejecución de los contratos (36). De este modo, se prevé la posibilidad de incorporar criterios sociales y ambientales en cuatro fases del proceso de contratación: como requisitos de calificación social y ambiental del contratista previos a la admisión al proceso de licitación; como especificaciones técnicas de los contratos; como criterios de adjudicación de los contratos; y, finalmente, como condiciones de ejecución del contrato (37).

La introducción, para el cálculo de la oferta económicamente más ventajosa del coste del ciclo de vida, supone una novedad importante de esta directiva (38), que opera como uno de los elementos a través de los cuales pueden incorporarse criterios sociales y ambientales.

Además de favorecer la introducción a los criterios sociales, la directiva muestra, posiblemente en mayor medida, una clara tendencia de impulso de la compra pública verde a través de los denominados criterios ambientales (39). Debe resaltarse también el refuerzo de los principios de

(36) MARTÍNEZ FERNÁNDEZ, José Manuel: «Avanzando en Contratación socialmente responsable: de la recomendación a la obligación", cit.

(37) Siguiendo la síntesis realizada en GONZÁLEZ GARCÍA, José Vicente: «Sostenibilidad social y ambiental en la Directiva 2014/24/UE de Contratación Pública», cit., págs. 35-42. También MARTíNEZ FERNÁNDEZ, José Manuel.: "Avanzando en Contratación socialmente responsable: de la recomendación a la obligación», cit.

(38) Sobre la valoración de ofertas, vid., DOMENECH PASCUAL, Gabriel: «La valoración de las ofertas en el derecho de los contratos públicos", en Revista General de Derecho Administrativo (lustel), núm. 30, 2012.

(39) SARASÍBAR IRIARTE, Miren: "La contratación pública se tiñe de verde», en GIMENO FELIÚ, José María, GALLEGO CÓRCOLES, Isabel, HERNÁNDEZ GONZÁLEZ, Francisco, MOLINA MORENO, José Antonio, et. al.: Observatorio de los Contratos Públicos. Número monográfico especial 2015. Las nuevas Directivas de Contratación Pública (Ponencias sectoriales X Congreso Asociación Española Profesores de Derecho Administrativo). Universidad de Zaragoza - Ministerio de Economía y Competitividad, Thomson Reuters-Aranzadi, Cizur Menor (Navarra), 2015, págs. 317-328, pág. 319. 
transparencia, libre concurrencia e igualdad de los licitadores a través de instrumentos específicos (40).

En definitiva, destaca el significativo avance que la directiva 24/2014/ UE ha supuesto para la incorporación de criterios sociales y ambientales, en consonancia con los objetivos buscados en Europa 2020, si bien el principio de la libre competencia sigue operando como un límite a la incorporación de criterios sociales y ambientales, cuando perfectamente podrían incorporarse los valores de innovación, y responsabilidad social y ambiental como criterios que dirigieran la libre competencia entre los operadores económicos hacia la consecución de los objetivos de Europa 2020.

\section{La aplicación práctica de criterios sociales a través de la doctrina de los tribunales administrativos de contratos públicos}

La aplicación práctica de criterios sociales y ambientales ha sido analizada a través de diversas resoluciones y recomendaciones tanto de los distintos Tribunales Administrativos de Contratos Públicos, como de las Juntas Consultivas, tanto estatal como autonómicas, que, junto con algunos OCEX se han pronunciado al respecto, recomendando, en ocasión, la inclusión de este tipo de criterios en los pliegos de condiciones (41).

Entre todas ellas resulta destacable el Informe 16/2014, de 1 de octubre, de la Junta Consultiva de Contratación Administrativa de Aragón (42), que enmarca la posibilidad de incorporar criterios sociales como condi-

(40) ALONSO GARCíA, María Consuelo: «Las novedades introducidas por la Directiva 2014/24/UE en la contratación pública verde", en GIMENO FELIÚ, José María, GALLEGO CÓRCOLES, Isabel, HERNÁNDEZ GONZÁLEZ, Francisco, MOLINA MORENO, José Antonio, et. al.: Observatorio de los Contratos Públicos. Número monográfico especial 2015. Las nuevas Directivas de Contratación Pública (Ponencias sectoriales X Congreso de la Asociación Española Profesores de Derecho Administrativo). Universidad de Zaragoza - Ministerio de Economía y Competitividad, Thomson Reuters-Aranzadi, Cizur Menor (Navarra), 2015, pág. 279-289, pág. 288.

(41) Además de los mencionados en el presente trabajo, MARTíNEZ FERNÁNDEZ recopila algunos pronunciamiento como: IJCCAE 14/2013; IJCCA de Aragón 1/2015, de 17 de marzo; IJCCA de Cataluña 18/2014, de 17 de diciembre; RTACRC 56/2015, de 20 de enero; RTACRC 891/2014, de 5 de diciembre; STSJ del País Vasco 617/2014, de 30 de diciembre de 2014, rec. 630/2014 (que valida la citada Norma Foral 4/2013 de Gipuzkoa), Informe de 24 de octubre de 2014 del Consello de Contas de Galicia Contratación Administrativa 2010-2011), Informes del Tribunal de Cuentas n. ${ }^{\circ} 1085$, de 26 de marzo de 2015 y n. ${ }^{\circ} 1022$, de 30 de enero de 2014), RTACR 891/2015, sin embargo, por razones de espacio, únicamente me referiré a algunos de ellos, por exceder una análisis más exhaustivo, del objeto de este artículo. MARTÍNEZ FERNÁNDEZ, José Manuel: «Avanzando en contratación socialmente responsable: de la recomendación a la obligación", cit.

(42) El Informe responde a una consulta del Vicealcalde y Consejero de Presidencia de Ayuntamiento de Zaragoza en relación con la aprobación, por el Pleno de la corporación, de una moción en la que se instaba al Gobierno de la Ciudad a incorporar, como como condición de ejecución de contrato, la obligación del contratista de no minorar las condiciones laborales durante el tiempo de prestación del contrato, con la correspondiente penalidad por incumplimiento. 
ciones de ejecución de los contratos dentro del amparo del artículo 118 TRLCSP, que establece la necesidad de cumplir con dos límites: que dicha condición no resulte directa ni indirectamente discriminatoria, y que el contenido de la misma se contenga en el anuncio de licitación y en el pliego de condiciones del contrato. Cuestión que encuentra más amplio acomodo bajo la protección de la Directiva 2014/24/UE, que, no obstante, incide en los mismos límites señalados.

Por su parte, el Tribunal Administrativo de Contratos Públicos de Aragón, en su Acuerdo 72/2016, de 14 de julio de 2016, se refirió a la incorporación de condiciones sociales, siendo reseñable el Fundamento de Derecho cuarto de dicho Acuerdo, que, siguiendo la doctrina fijada por el Tribunal Administrativo de Contratación Pública de la Comunidad de Madrid (43), y siguiendo reconoce la posibilidad de incorporar criterios sociales como marco del diseño de un contrato en tanto que política pública, aunque siempre que guarde vinculación directa o indirecta con el objeto del contrato, de acuerdo con la doctrina jurisprudencial delTJUE.

Así, y en cuanto a dicha relación, la misma no puede resultar "forzada", ni interferir indebidamente en la propia política empresarial de los licitadores. Debe ponerse en valor, no obstante, el reconocimiento que el Acuerdo contiene, en el sentido de que la contratación pública puede diseñarse al servicio de intereses sociales, aunque, en todo momento, dejando claros los límites de la no distorsión de la competencia, de no introducir controles indebidos «en la legítima gestión de intereses empresariales". Así, tal y como señala elTACPA, la función regulatoria del contrato de los pliegos no puede resultar sobrepasada proyectando efectos sobre la organización empresarial de los licitadores. Todo lo cual se recoge en STS 1156/2016, de 18 de mayo, que prescribe que mediante un contrato público no puede variarse la legislación laboral.

No obstante lo anterior, no se considera que vulnere tales consideraciones la introducción de cláusulas que contengan la obligación de subrogación de trabajadores, siempre que la misma se derive de un deber legal o convencional, de acuerdo con lo preceptuado por la propia directiva 2014/24/UE, y sentando que el coste derivado de la subrogación debe considerarse a la hora de calcular el valor estimado del contrato.

Tampoco puede reputarse contrario a Derecho exigir a la empresa adjudicataria que mantenga un determinado nivel retributivo a sus trabajadores, ya que, de acuerdo con el artículo 67 de la directiva de 2014, las características sociales forman parte de los criterios de calidad, que deben ser tenidos en cuenta a la hora de valorar la mejor relación calidad-precio, siempre de acuerdo con la doctrina de la sentencia RegioPost. Además,

(43) Resolución 16/2016 delTribunal Administrativo de Contratación Pública de Madrid. 
ha de tenerse en cuenta que la oferta forma parte del pliego de condiciones, y constituye la lex contractus, además de traer a colación el principio general de pacta sunt servanda. Quien oferta unas condiciones, debe mantenerla durante el tiempo de duración del contrato.

No obstante, como recuerda el Informe 1/2016, de la Junta Consultiva de Contratación Administrativa de Aragón, dichos criterios deben especificarse "con la suficiente precisión y exactitud" en los pliegos, de acuerdo con el principio de transparencia, y para permitir a los licitadores la evaluación de los costes del contrato.

Por otro lado, la Resolución n. ${ }^{\circ}$ 210/2016, de 18 de marzo, del Tribunal Administrativo Central de Contratos Públicos, asevera que la introducción de criterios sociales debe condicionarse a dos parámetros: que guarde relación directa con el objeto del contrato, y que no resulten discriminatorios. En este sentido, entronca con la jurisprudencia comunitaria establecida desde Beentjes, así como con el texto de la Directiva 2014/24/UE, y con el propio articulado delTRLCSP, si bien obvia la resolución los requisitos de cumplir con el principio de transparencia, a través de su mención expresa en el anuncio de licitación y en el pliego de condiciones, y, en general con los principios del derecho europeo, especialmente con el principio de libre competencia.

No debemos obviar que, tal y como ha señalado la Resolución 44/2007, de 1 de marzo, del Tribunal Catalán de Contratos del Sector Público, a la hora de determinar el objeto del contrato, ha de tenerse en cuenta, por un lado, que no se trate de una prestación claramente diferenciable, que, como tal, pueda ser objeto de una licitación por separado, $y$, en segundo lugar, que la finalidad social que quiere fomentarse pueda realizarse sobre la propia prestación principal. Así, las cláusulas sociales que quieran incorporarse al objeto del contrato, han de poder ser realizadas por el adjudicatario a través de la materia a suministrarse o de la prestación concreta a realizar, dado que se trata de un elemento que debe poder relacionarse intrínsecamente con la prestación principal.

Además, la misma resolución advierte de la necesidad de que la cláusula social en cuestión, sea objetivable desde un punto de vista económico, y, en este sentido, quede claramente determinada, ya que los costes derivados de la misma deben ser tenidos en cuenta a la hora de cuantificar económicamente la oferta.

La doctrina de los organismos administrativos de control de la contratación pública sigue la línea general marcada, en primera instancia, por la jurisprudencia europea, positivizada en las directivas y transpuesta en, en un primer momento en el TRLCSP de 2007 y posteriormente en el Proyecto de LCSP de 2016. Así, no sólo reconocen la posibilidad de incorporar distintos criterios sociales en las diferentes fases del proceso de contratación, sino que lo encuentran deseable, en el marco del diseño, a 
través de la contratación pública, de políticas para la incorporación al mercado laboral de colectivos con difícil empleabilidad, el fomento de la igualdad efectiva entre mujeres y hombres, la lucha contra el desempleo, o el mantenimiento de unas condiciones laborales dignas para el personal al servicio de las empresas adjudicatarias. Sin embargo, la prioridad la sigue estableciendo, fundamentalmente, el principio de la libre competencia, que continúa presentándose como incompatible con el impulso a una contratación pública responsable desde el punto de vista social, ambiental y de la innovación. Y, llegados a este punto, lo anterior sugiere una reflexión: ¿acaso no es posible conjugar ambos valores y avanzar hacia una competencia libre entre licitadores que, precisamente, pugne por presentar la mejor oferta también desde una perspectiva social, ambiental e innovadora, coadyuvando, no sólo al cumplimiento de los objetivos de Europa 2020, sino a la mejora de la sociedad en general?

\section{Los criterios sociales en el Proyecto de Ley de Contratos del Sector Público}

El proyecto de Ley de Contratos del Sector público tiene como principal objeto actualizar el régimen de contratos del sector público a través de la transposición, por otro lado tardía, de las directivas de cuarta generación.

La tramitación del proyecto se planteó en primera instancia de una manera inusitadamente acelerada, sin apenas plazo de enmiendas para los grupos parlamentarios. El efecto de ello ha sido la ampliación del plazo de enmiendas por 10 veces, la última finalizada el 2 de marzo de 2017.

Dicho apresuramiento bien podría estar motivado por prisas repentinas de última hora, o más probablemente, por una excesiva concepción tecnicista del régimen de contratos públicos que parece no considerar la importancia del Parlamento para solucionar los actuales retos de la contratación pública, que son, esencialmente, problemas de naturaleza política (44).

(44) Martín RAZQUÍN LIZARRAGA ha señalado que «Con todo, estimo que lo más relevante se encuentra en que los problemas que acucian a la contratación pública son de naturaleza política (no técnica o por lo menos no eminentemente técnica) y deben por tanto adoptarse criterios políticos que luego se plasmarán en los correspondientes preceptos legales. Apunto aquí algunos aspectos: El imperio de los principios generales: integridad, igualdad, transparencia y competencia. Alcance del ámbito subjetivo de la Ley y su aplicación - por qué y en qué medida total o parcial- a todo el sector público. La simplificación de los procedimientos de contratación.

El fomento de la innovación, como motor económico. Las vías de recurso para asegurar el cumplimiento de la legalidad en materia de contratos públicos. La procedencia o no de mantener de forma tan rígida la summa divisio entre contratos superiores e inferiores al umbral comunitario. La adecuación de los procedimientos a los pequeños y medianos municipios. La electronización de la contratación pública. 
En cualquier caso, y a la espera de las enmiendas que puedan plantear los grupos parlamentarios, procede analizar el tratamiento que el proyecto de ley da a las consideraciones sociales.

De la Exposición de Motivos podría derivarse un interés de los redactores del proyecto por cumplir con los objetivos de la Estrategia Europa 2020 (expositivo I).

Asimismo, se señalan como objetivos del proyecto lograr una mayor transparencia, una mejor relación calidad-precio a través de la introducción de nuevas consideraciones, como son la prioridad que debe darse a la calidad, así como a cuestiones ambientales, sociales y de innovación (expositivo II).

Más precisamente, en lo que hace a los criterios sociales y ambientales, la exposición de motivos asevera que la Ley pretende fomentar el uso de la contratación pública como instrumento para implementar políticas en materia ambiental, social, de innovación, de promoción de las PYMES y de defensa de la competencia. Incluso va más allá, afirmando que tales elementos constituyen los "verdaderos objetivos del proyecto» (expositivo III).

La cuestión es ¿responde el articulado a las pretensiones fijadas en la exposición de motivos?, es decir, ¿realmente son las consideraciones sociales, ambientales y de innovación los verdaderos objetivos buscados por el proyecto?

Así, contrasta el objeto y finalidad de la Ley establecido en el artículo 1 con los fines aseverados en la exposición de motivos. A pesar de lo señalado en ésta, el artículo 1 no sólo omite toda referencia a los objetivos de Europa 2020 sino que obvia toda referencia a la búsqueda, a través de la contratación pública, de objetivos sociales, ambientales y de innovación, consideraciones que bien podrían haberse incluido, siquiera genéricamente, a la hora de enunciar los objetivos y fines del proyecto de ley (45).

\footnotetext{
Además, la Ley no puede convertirse en un simple papel que lo aguanta todo, sino que tiene que ajustarse a la realidad en orden a garantizar su cumplimiento".

Vid. RAZQUIN LIZARRAGA, Martín María: «El proyecto de ley de contratos del sector público. Una tramitación parlamentaria acelerada", en Observatorio de Contratos del Sector Público, www.obcp. es, diciembre de 2016, documento electrónico.

(45) Manuel Gómez Ruiz propone en su tesis doctoral, una redacción alternativa a la marcada por el Anteproyecto, con la siguiente literalidad: «La presente Ley tiene por objeto regular la contratación del sector público, a fin de garantizar que la misma se ajusta a los principios de libertad de acceso a las licitaciones, publicidad y transparencia de los procedimientos, y no discriminación e igualdad de trato entre los candidatos; $y$ de asegurar, en conexión con el objetivo de estabilidad presupuestaria, control del gasto, integración de consideraciones ecosociales y el principio de integridad, una eficiente utilización de los fondos destinados a la realización de obras, la adquisición de bienes y la contratación de servicios mediante la exigencia de la definición previa de las necesidades a satisfacer, la salvaguarda de la libre competencia y la selección de la oferta económicamente más ventajosa». Vid. GÓMEZ RUIZ, Manuel: Aspectos sociales y medioambientales en la contratación pública. Universidad de Cádiz. Tesis Doctoral dirigida por D. ${ }^{a}$ María Zambonino Púlito, leída el 19/01/2016, pág. 411.
} 
Sí debe reconocerse un cierto avance en la materia con respecto al TRLCSP (46), que los introduce en diferentes fases de la contratación como son la prohibición de contratar a las empresas que hubieran incumplido las obligaciones legales o convencionales en materia laboral, fiscal o ambiental, los criterios de adjudicación del contrato (art. 145), el cálculo del ciclo de vida (art. 146), como condición especial de ejecución del contrato (art. 200). Sin olvidar la extensión a empresas de inserción de la regulación que contiene de las reservas a centros especiales de empleo, o de reserva de ejecución en el marco de programas de empleo protegido (d.a. 4 . $^{\mathrm{a}}$.

En cuanto a las prohibiciones de contratar, el artículo 71 del proyecto apenas contiene diferencias con respecto al artículo 60 TRLCSP, de manera que éstas siguen fijándose para quienes hayan sido condenados por sentencia firme por fraudes, delitos contra la Hacienda Pública y la Seguridad Social o delitos contra los trabajadores. También continúa en similares términos la prohibición de contratar para las empresas que hubieran sido sancionadas por infracción grave en materia de integración laboral y de igualdad de oportunidades y no discriminación de personas con discapacidad, o de extranjería, o por infracción muy grave en materia ambiental. Del mismo modo, sigue fijada la prohibición para las empresas que se hallen al corriente del cumplimiento de las obligaciones tributarias o con la Seguridad Social, y aquellas con más de 50 trabajadores que no cumplan el requisito de que al menos el $2 \%$ de sus empleados sean personas con discapacidad (47).

Tampoco se aprecian modificaciones, en cuanto a la incorporación de indicadores de la gestión medioambiental como elemento para valorar la solvencia técnica en los contratos de obra y en los contratos de servicios, ya que los artículos 88 y 90 del proyecto contienen la misma dicción literal que los artículos 76 y 78 del vigenteTRLCSP.

Sí contiene un avance en cuanto a la incorporación de consideraciones sociales el artículo 145 PLCSP, que regula los criterios de adjudicación del contrato.

Criterios de adjudicación que, tal y como establece la jurisprudencia delTJUE, deberán tener vinculación con el objeto del contrato, estar de-

(46) VALCELILLO GÁMEZ, María Rosa y GUTIÉRREZ GONZÁLEZ, Juan Jesús: «La responsabilidad social pública como elemento de política de empleo", en CIRIEC-España, Revista de Economía Pública, Social y Cooperativa, núm. 87, 2016, pág. 1-28.

(47) Sobre las prohibiciones de contratar en la jurisprudencia europea, vid. MEDINA ARNAIZ, Teresa: "La aplicación de las prohibiciones de contratar según la jurisprudencia del Tribunal de Justicia de la Unión Europea», en GIMENO FELIÚ, José María, GALLEGO CÓRCOLES, Isabel, HERNÁNDEZ GONZÁLEZ, Francisco, MORENO MOLINA, José Antonio, et. al.: Las nuevas directivas de contratación pública (X Congreso de la AEPDA). Thomson Reuters Aranzadi - Universidad de Zaragoza, pág. 383-394. 
bida y objetivamente fijados en el anuncio de licitación y en el pliego de condiciones, respetar los principios de la contratación pública (igualdad, no discriminación, transparencia y proporcionalidad), no otorgar un poder de decisión ilimitado al órgano de contratación, y deberán garantizar que las ofertas sean evaluadas en condiciones de competencia efectiva.

Se establecen dos tipos de criterios de adjudicación: los relacionados con los costes, incluida la relación coste-eficacia, y el cálculo del coste del ciclo de vida, para cuyo cálculo, el artículo 146 permite observar las externalidades de los costes ambientales (48).

$\mathrm{Y}$, por otro lado, los criterios cualitativos, orientados a identificar la oferta que suponga la mayor relación calidad-precio. En estos segundos, $\mathrm{y}$, en concreto, en lo que hace a la valoración de la calidad, se prevé contemplar las características sociales, ambientales e innovadoras. Esta formulación parece ir más allá del artículo 150 delTRLCSP.

Además, el mismo artículo 145.9 prevé la inclusión de criterios sociales como cláusulas de desempate, priorizando a aquellas empresas que tengan un número de trabajadores con discapacidad superior al $2 \%$, entre otras cuestiones (49).

No obstante, y si bien hay que reconocer que el artículo 145 avanza en cuanto a la incorporación de cláusulas sociales, no puede negarse que, en parte, "se queda corto", teniendo en cuenta que el Programa Nacional de Reformas de 2014, proponía que la adjudicación recayera siempre en la "oferta económica y social más ventajosa», o que bien podría haber establecido que los criterios sociales de desempate fueran de contenido obligatorio y no meramente potestativo, como señala el artículo $145.9(50)$.

Además, el PLCSP prevé la incorporación de criterios sociales como condiciones especiales de ejecución de los contratos, siempre que estén vinculadas al objeto del contrato, no resulten discriminatorias, sean compatibles con el derecho europeo, y queden debidamente indicadas en el anuncio de licitación y en el pliego del contrato.

(48) GIMENO FELIÚ, José María: «Hacia una nueva Ley de Contratos del Sector Público. ¿Una nueva oportunidad perdida?», en REDA, n. ${ }^{\circ} 182$, enero-marzo 2017, págs. 181-221, pág. 214.

(49) El artículo 145.9 PLCSP establece una serie de prioridades en caso de desempate que se concreta en el número de trabajadores con discapacidad, que se trate de empresas de inserción reguladas en la Ley 44/2007, en el caso de contratos relativos a prestaciones de carácter social o asistencial, que se trate de entidades sin ánimo de lucro cuya actividad guarde relación directa con el objeto del contrato, que se trate de organizaciones de Comercio Justo, y aquellas empresas que hayan ofertado medidas de carácter social y laboral que favorezcan la igualdad entre ambos sexos.

(50) VALLECILLO GÁMEZ, María Rosa, y GUTIÉRREZ GONZÁLEZ, Juan Jesús: «La responsabilidad social pública como elemento de política de empleo", cit., pág. 20. 
Entre las mismas, se contempla un listado, que constituye un numerus apertus de posibles condiciones especiales de ejecución de tipo social.

No obstante, se trata de una opción que el legislador deja en manos de los órganos de contratación, excluyendo cualquier posibilidad de obligatoriedad al respecto

En cualquier caso, una vez establecidas, sí se prevé la posibilidad de establecer penalidades motivadas por el incumplimiento por parte del adjudicatario de dichas condiciones especiales de ejecución.

Finalmente, la disposición adicional cuarta regula la reserva de contratos a Centros Especiales de Empleo y a empresas de inserción reguladas en la Ley 44/2007.

Así pues, la introducción de criterios de carácter social está prevista en distintos momentos del proceso de contratación, destacando la posibilidad de incorporarlas entre los criterios de adjudicación y como condiciones especiales de ejecución.

No obstante, el PLCSP, si bien introduce algunas novedades, no contiene los avances que podría haber introducido a la luz del cambio de paradigma que supone la cuarta generación de directivas, que avanza, de acuerdo con la estrategia Europa 2020, hacia lo que J.M. GIMENO ha denominado "perspectiva instrumental» de la contratación, por la cual la contratación pública debe articularse como un medio para lograr un crecimiento inteligente basado en consideraciones sociales, ambientales y de innovación. Para ello, la incorporación de criterios sociales en las diferentes fases de la contratación es necesaria, ya que la misma debe servir para lograr el cumplimiento de tales objetivos sociales, ambientales y de investigación (51).

Pues bien, aun reconociendo ciertos avances en éste campo, no podemos obviar que la norma de transposición no despliega todas las posibilidades que abre la Directiva 24/2014, y continúa con la misma visión de la contratación pública del anterior TRLCSP. De esta manera, no contiene el necesario impulso a la sostenibilidad ambiental, social y de innovación que el estrecho campo de la cuarta generación de directivas y la jurisprudencia comunitarias le hubiera permitido, de manera que cuestiones trascendentales como la igualdad salarial, los planes de formación o la estabilidad en el empleo, no encuentran todo el impulso que debieran (52).

(51) GIMENO FELIÚ, José María: «Hacia una nueva Ley de Contratos del Sector Público. ¿Una nueva oportunidad perdida?", cit. págs. 183 y 184.

(52) GONZÁLEZ GARCÍA, José Vicente, "Nueva Ley de Contratos. Aspectos para modificar», en su blog www.globalpoliticsandlaw.com, documento electrónico. 


\section{Conclusiones}

Teniendo en cuenta el peso que ha adquirido la contratación pública en toda la Unión Europea, y con base en la estrategia Europa 2020, la contratación pública, a partir de la cuarta generación de Directivas Europeas, debe avanzar hacia un nuevo paradigma que la resitúa en términos instrumentales, como un medio para conseguir objetivos ambientales, sociales y de innovación.

En este sentido, los principios clásicos de la contratación pública, (igualdad de oportunidades, igualdad de trato y no discriminación, proporcionalidad, confianza legítima, confidencialidad y transparencia) han de completarse con la búsqueda de fines sociales, ambientales y de innovación. Además de lograr la obtención de bienes y servicios a través de un procedimiento garantista basado en la libre competencia, los procedimientos de contratación deben velar, por lograr un mejor nivel de empleo, unas condiciones laborales dignas, una mayor integración social y un crecimiento económico ambientalmente sostenible. Cuestiones éstas que también han de considerarse a la hora de ponderar el interés público en la contratación administrativa.

Probablemente ello requiera avanzar hacia una nueva concepción del principio de la libre competencia que integre los elementos sociales, ambientales y de innovación como valores para lograr una competitividad sostenible y racional entre los operadores económicos, que permitan un crecimiento integrador. Es decir, no se trata de optar por quien garantice el mejor servicio a cambio del mejor precio, sino por quien garantice el mejor servicio a cambio del mejor precio dejando la menor huella ambiental, garantizando unas condiciones de empleo dignas, integrando a personas en situación de difícil empleabilidad, integrando en el mercado laboral a personas con discapacidad, reduciendo las desigualdades entre sexos, o fomentando la innovación en las empresas. Que la empresa más competitiva sea la que más integre socialmente, la que más respete el medio ambiente y la que aporte mayor innovación tecnológica, y no la que sea capaz de lograr el mejor balance coste-beneficio sin tener en cuenta consideraciones sociales, ambientales y de innovación.

Y para ello hay campo abierto tanto en la jurisprudencia comunitaria como en la cuarta generación de Directivas Europeas.

No obstante, no se trata de un campo ilimitado, ya que, como recuerda toda la jurisprudencia europea, desde Beentjes hasta RegioPost, la inclusión de criterios sociales está condicionada a que los mismos guarden relación con el objeto del contrato, deberán publicitarse y concretarse en el anuncio de licitación o en el pliego de condiciones, no podrán otorgar un poder ilimitado de elección al poder adjudicador y deberán so- 
meterse a los principios básicos del Derecho de la UE, y muy especialmente al principio de libre concurrencia y no discriminación.

Condicionamientos, todos ellos, que van dirigidos a garantizar la libre concurrencia entre empresas licitadoras, $y$, que, por tanto, condicionan la incorporación de cláusulas sociales y ambientales a la garantía de los principios de la competencia.

$Y$ es que no podemos obviar la existencia de una dialéctica constante entre la inclusión de dichos criterios y los principios de la competencia.

De esta manera, si bien la incorporación de criterios sociales y ambientales en los procedimientos de licitación se encuentra fundamentada sobre la base del TFUE y ha sido objeto de invocación por parte de relevantes instrumentos de soft law impulsados por la Comisión, lo cierto es que, a la hora de valorar su incorporación práctica, el TJUE siempre la ha supeditado a la no afección de la libre competencia entre licitadores.

Lo anterior se ha visto reflejado en la Directiva 2014/24/UE, que aunque sin desprenderse de la doctrina clásica, en cuanto a la primacía que adquiere el principio de libre competencia sobre la perspectiva social de la contratación pública, ha dado un importante paso adelante en la materia.

No en vano, además de ratificar los condicionamientos establecidos en la doctrina jurisprudencial y positivizados en la anterior generación de directivas, promueve las reservas de contratos para talleres de empleo protegido, permite la valoración de criterios sociales y ambientales para la calificación del contratista, regula la inclusión de consideraciones sociales y ambientales entre las especificaciones técnicas del contrato, contiene la posibilidad de establecer cláusulas de esta misma naturaleza como criterios de adjudicación y, asimismo, regula la posibilidad de que el poder adjudicador tenga en cuenta cláusulas sociales y ambientales entre los criterios de ejecución del contrato.

En particular destaca la inclusión en el artículo 18.2, a continuación de la proclamación de los principios de la contratación pública, de un Ilamamiento a los Estados miembros para tomar las medidas necesarias a fin de garantizar el cumplimiento por parte de los operadores económicos de las obligaciones de tipo social medioambiental y laboral, unido a la consideración del incumplimiento de dichas obligaciones entre las causas de exclusión, supone un avance significativo en la materia.

Todo ello ha tenido su reflejo en la práctica contractual, tal y como se desprende de los reiterados acuerdos, informes y resoluciones de los Tribunales Administrativos de Contratación Pública, de las Juntas Consultivas de Contratación Administrativa y de los OCEX en general, que no sólo señalan de la posibilidad de incorporar criterios sociales en la contratación pública, sino que, en ocasiones, incluso señalan la conveniencia de su incorporación. 
Y en esta situación se presenta ante las Cortes Generales, no sin un más que significativo retraso, el PLCSP que transpone la Directiva 24/2014 al ordenamiento jurídico interno. El texto contiene la posibilidad de tener en cuenta consideraciones sociales en diversas fases de la contratación, entre las que hay que destacar el artículo 145, que prevé la inclusión de consideraciones sociales entre los criterios de adjudicación, el artículo 200, sobre condiciones especiales de ejecución, y la reserva de contratos a CEEs contenida en la disposición adicional cuarta.

No puede negarse un importante avance en la materia con respecto al TRLCSP. Pero tampoco puede obviarse una cierta decepción, en el sentido que no se aprovecha el campo de acción que, sobre la materia, permite la Directiva 24/2014 y el nuevo paradigma que comprende, de entender la contratación pública como un medio para conseguir un crecimiento sostenible e integración desde la perspectiva social, ambiental y de innovación. Parece claro que el articulado no responde a las expectativas de la Exposición de Motivos.

En este sentido, llama la atención cómo el texto del PLCSP se queda por detrás, incluso, del Programa Nacional de Reformas de 2014.

$Y$ en el fondo de todo, queda en el aire la siguiente pregunta: ¿asumirá el legislador interno el nuevo paradigma europeo en la Contratación Pública?

La resolución del trámite de enmiendas y el resultado final de la futura Ley nos lo dirá.

\section{Bibliografía}

ALONSO GARCÍA, María Consuelo: "Las novedades introducidas por la Directiva 2014/24/UE en la contratación pública verde», en GIMENO FELIÚ, José María, GALLEGO CÓRCOLES, Isabel, HERNÁNDEZ GONZÁLEZ, Francisco, MOLINA MORENO, José Antonio, et. al.: Observatorio de los Contratos Públicos. Número monográfico especial 2015. Las nuevas Directivas de Contratación Pública (Ponencias sectoriales $X$ Congreso de la Asociación Española Profesores de Derecho Administrativo). Universidad de Zaragoza - Ministerio de Economía y Competitividad, Thomson Reuters-Aranzadi, Cizur Menor (Navarra), 2015, pág. 279-289.

AYMERICH CANO, Carlos, y FERREIRA FERNÁNDEZ, Antonio Javier: «EI tratamiento de las cláusulas sociales en la normativa reguladora de la Contratación Pública. En particular las cláusulas sociales como criterio de adjudicación de los contratos", en PERNÁS GARCÍA, Juan José, RODRíGUEZ-ARANA MUÑOZ, Xaime (coords.), JINESTA LOBO, Ernesto, (Dir.): El Derecho Administrativo en perspectiva: en homenaje al profesor José Luis Meilán Gil. RAP editores, Buenos Aires, 2014, tomo II, pág. 33-52. 
BALLINA DÍAZ, Diana: "Las cláusulas sociales en la contratación pública», en El consultor de los Ayuntamientos y de los Juzgados, núm. 3, 2011, pág. 296-302.

BENACCHIO, G.A.: "Verso le Direttive di quarta generazione», en BENACCHIO, G.A., y COZZIO, M.: Gli appalti pubblici: tra regole europee e nazionali. Egea, Milano, 2012, pág. 3-28.

CARANTA, Roberto y TRYBUS, Martin (Eds.): The Law of Green and Social Procurement in Europe (European Procurement Law). DJOF Publishing, Copenhague, 2010.

DOMENECH PASCUAL, Gabriel: "La valoración de las ofertas en el derecho de los contratos públicos», en Revista General de Derecho Administrativo (lustel), núm. 30, 2012.

GALLEGO CÓRCOLES, Isabel: "Cláusulas sociales, contratación pública y jurisprudencia del TJUE», en Contratación Administrativa Práctica, núm. 113, 2011, pág. 64-69.

GIMENO FELIÚ, José María: La contratación pública europea y su incidencia en la legislación española. La necesaria adopción de una nueva ley de contratos públicos y propuestas de reforma. Thomson Aranzadi, Cizur Menor (Navarra), 2006.

GIMENO FELIÚ, José María: La nueva contratación pública europea y su incidencia en la legislación española. Civitas, Madrid, 2006.

GIMENO FELIÚ, José María: "Las nuevas Directivas - cuarta generación- en materia de contratación pública. Hacia una estrategia eficiente de compra pública», en Revista española de Derecho Administrativo, núm. 159, 2013.

GIMENO FELIÚ, José María: El nuevo paquete legislativo comunitario sobre contratación pública. De la burocracia a la estrategia. Thomson Aranzadi - Ministerio de Economía y Competitividad - Universidad de Zaragoza, Cizur Menor (Navarra), 2014.

GIMENO FELIÚ, José María: "Un paso firme en la construcción de una contratación pública socialmente responsable mediante colaboración con entidades sin ánimo de lucro en prestaciones sociales y sanitarias", en Observatorio de la Contratación Pública, 2016 (documento electrónico).

GIMENO FELIÚ, José María: «Novedades del Anteproyecto de Ley de Contratos del Sector Público. La transposición de las Directivas de contratación pública en España», ponencia presentada en el Congreso Internacional sobre Contratación Pública, celebrado en Cuenca los días 21 y 22 de enero de 2016, organizado por el Observatorio de Contratación Pública y la Universidad de Castilla La Mancha.

GIMENO FELIÚ, José María: "Hacia una nueva Ley de Contratos del Sector Público. ¿Una nueva oportunidad perdida?», en REDA, n. ${ }^{\circ} 182$, eneromarzo 2017, págs. 181-221, pág. 214. 
GÓMEZ RUIZ, Manuel: Aspectos sociales y medioambientales en la contratación pública. Universidad de Cádiz. Tesis Doctoral dirigida por D. ${ }^{a} \mathrm{Ma}-$ ría Zambonino Púlito, leída el 19/01/2016.

GONZÁLEZ GARCÍA, José Vicente: «Sostenibilidad social y ambiental en la Directiva 2014/24/UE de Contratación Pública» en Civitas. Revista Española de Derecho Europeo, núm. 56, 2015, págs. 13-42.

GONZÁLEZ GARCÍA, José Vicente: "Nueva Ley de Contratos. Aspectos para modificar», en su blog www.globalpoliticsandlaw.com, documento electrónico.

KUNZIL, P.: "Green procurement under the new regime», en NIELSE, R., TREUMER, S.: The new EU procurement directives. DJ F Publishing, Copenhague, 2005.

LEFÈVRE, P. : "Les considérations sociales et environnementales dans les marchés publics européens", en Journal des Tribunaux. Droit européen, núm. 7, 2000.

LESMES ZABALEGUI, Santiago: "Contratación pública y discriminación positiva. Cláusulas sociales para promover la igualdad de oportunidades entre mujeres y hombres en el mercado laboral», en Lan Harremanak, núm. 13, 2005, pág. 53-86.

MARCHAL ESCALONA, Nuria: "Las cláusulas sociales en los contratos públicos: ¿son contrarias al Derecho comunitario?», en Bitácora Millenium DIPr. Derecho Internacional Privado, núm. 3, 2016, pág. 12-26.

MARTÍNEZ FERNÁNDEZ, José Manuel: Avanzando en la Contratación socialmente responsable: de la recomendación a la obligación. Observatorio de la Contratación Pública, 2011 (documento electrónico).

MEDINA ARNAIZ,Teresa: «Más allá del precio: las compras públicas con criterios de responsabilidad (I)», en Actualidad Administrativa, núm. 113, 2013.

MEDINA ARNAIZ, Teresa: "La aplicación de las prohibiciones de contratar según la jurisprudencia del Tribunal de Justicia de la Unión Europea», en GIMENO FELIÚ, José María, GALLEGO CÓRCOLES, Isabel, HERNÁNDEZ GONZÁLEZ, Francisco, MORENO MOLINA, José Antonio, et. al:: Las nuevas directivas de contratación pública ( $X$ Congreso de la AEPDA). Thomson Reuters Aranzadi - Universidad de Zaragoza, págs. 383-394.

MEDINA JURADO, Purificación: "Las cláusulas sociales en la contratación pública: retos y perspectivas", en Revista CEMCl, núm. 7, 2010.

MELERO ALONSO, Eduardo Y ESPÍN SÁEZ, Maravillas: «El contrato administrativo como instrumento para ejercer políticas públicas. Fomento del empleo estable y contratación con empresas de trabajo temporal", en Revista Jurídica de la Comunidad de Madrid, núm. 1, 1999, documento electrónico.

MORCILLO MORENO, Juana: "Las cláusulas sociales en la contratación pública como garantía al dumping social intracomunitario», en Revista Aragonesa de Administración Pública, núm. 47-48, 2016, pág. 180-209. 
MORENO MOLINA, José Antonio: "La cuarta generación de Directivas de la Unión Europea sobre contratos públicos», en GIMENO FELIÚ, José María, BERNAL BLAY, Miguel Ángel, (Coords.), et. al.: Observatorio de Ios Contratos Públicos, 2012. Thomson Reuters Aranzadi, Cizur Menor (Navarra), 2013.

PÉREZ ALCÁNTARA, A.J.: "Los principios de la contratación pública y la Ley de Contratos del Sector Público", en El Consultor de los Ayuntamientos y de los Juzgados, núm. 21, 2008.

PERNAS GARCÍA, Juan José: Contratación pública verde. La Ley Wolters Kluwer, Las Rozas (Madrid, 2011).

RAMOS PÉREZ-OLIVARES, Alfredo: "Las cláusulas sociales en la regulación de los contratos del sector público tras el R.D. Leg. 3/2011", en Contratación Administrativa Práctica, núm. 119, mayo de 2012, págs. 30-51.

RAZQUIN LIZARRAGA, Martín María: «Las nuevas Directivas sobre contratación pública de 2014: aspectos clave y propuestas para su transformación en España», en Revista de Administración Pública, núm. 196, págs. 97-113.

RAZQUIN LIZARRAGA, Martín María: «EI proyecto de ley de contratos del sector público. Una tramitación parlamentaria acelerada», en Observatorio de Contratos del Sector Público, www.obcp.es, diciembre de 2016, documento electrónico.

SARASÍBAR IRIARTE, Miren: "La contratación pública se tiñe de verde», en GIMENO FELIÚ, José María, GALLEGO CÓRCOLES, Isabel, HERNÁNDEZ GONZÁLEZ, Francisco, MOLINA MORENO, José Antonio, et. al.: Observatorio de los Contratos Públicos. Número monográfico especial 2015. Las nuevas Directivas de Contratación Pública (Ponencias sectoriales $X$ Congreso Asociación Española Profesores de Derecho Administrativo). Universidad de Zaragoza - Ministerio de Economía y Competitividad, Thomson Reuters-Aranzadi, Cizur Menor (Navarra), 2015, pág. 317-328.

VALCELILLO GÁMEZ, María Rosa y GUTIÉRREZ GONZÁLEZ, Juan Jesús: "La responsabilidad social pública como elemento de política de empleo", en CIRIEC-España, Revista de Economía Pública, Social y Cooperativa, núm. 87,2016 , pág. 1-28.

VILLALBA PÉREZ, Francisca: «La dimensión social de la contratación pública. El sector de la discapacidad en la Ley de Contratos del Sector Público», en Revista Andaluza de Administración Pública, núm. 74, 2009. 
LABURPENA: Europa 2020 estrategiak balioetsi duenez, kontratazio publikoa tresna egokia da sozialki integratzailea, berdea eta berrikuntza-sustatzailea izango den hazkundea lortzeari begira. Europar Batasuneko Justizia Auzitegiaren jurisprudentzia-doktrinak klausula sozialak sartzea onartu du, baina kontratazio publikoaren printzipioak (funtsean, lehia askea) ez mugatzeko baldintzapean. Horrela, bada, 2004ko zuzentarauek jurisprudentzia-doktrina positibizatu zuten. Zuzentarauen laugarren belaunaldiak, berriz, paradigma-aldaketa ekarri du. Horren bidez, kontratazio publikoa erabiltzen da gizarteratzeko politikak, ingurumen-politikak eta berrikuntza-politikak sustatzeko bitarteko apropos gisara. Sektore Publikoko Kontratuei buruzko Legearen proiektuaren bidez ari da jorratzen 2014/24 Zuzentarauaren transposizioa. Klausula sozialen arloan, kontratazio publikoaren paradigma berriari erantzuten al dio proiektuak? Kontu horixe jorratu nahi da lan honen bidez.

GAKO HITZAK: Kontratazio publikoa. Klausula sozialak. Kontratazio arduratsua. Sektore publikoa. Erosketa publiko berritzailea.

RESUMEN: La Estrategia Europa 2020 ha considerado que la contratación pública es un instrumento adecuado para lograr un crecimiento socialmente integrador, verde y que fomente la innovación. La incorporación de cláusulas sociales ha sido aceptada por la doctrina jurisprudencial del TJUE, aunque condicionada a no limitar los principios de la contratación pública, fundamentalmente la libre competencia. Así, las directivas de 2004 positivizaron la doctrina jurisprudencial. La cuarta generación de directivas, por su parte, ha introducido un cambio de paradigma que instrumentaliza la contratación pública como medio idóneo para el fomento de políticas de integración social, ambiental y de innovación. La transposición de la Directiva 2014/24 se está abordando mediante el Proyecto de Ley de Contratos del Sector Público. ¿Responde el proyecto al nuevo paradigma de la contratación pública en materia de cláusulas sociales? Esa es la cuestión que pretende abordarse a través del presente trabajo.

PALABRAS CLAVE: Contratación Pública. Cláusulas Sociales. Contratación Responsable. Sector Público. Compra Pública Innovadora.

ABSTRACT: The Europa 2020 strategy found public procurement to be an adequate tool for achieving a socially and green integrative growth and that promotes innovation. The incorporation of social clauses has been accepted by the case law doctrine of the EUCJ, although subjected to not to curtail public procurement principles, mainly free competition. Thus, 2004 Directives positivize the case law doctrine. The fourth generation of Directives, in turn, has introduced a paradigm shift that uses the public procurement as an ideal way to promote social integration, environment and innovation policies. The transposition of the directive 2014/24 is being carried out by means of the Bill on Public Contracts. Does this bill answer to the new paradigm in public procurement as far as social clauses are concerned? That is the issue we try to deal with in this work.

KEYWORDS: Public procurement. Social clauses. Responsible sourcing. Public Sector. Innovative Public Purchase. 